Article

\title{
Development of a Thermoelectric and Electromagnetic Hybrid Energy Harvester from Water Flow in an Irrigation System
}

\author{
Huicong Liu ${ }^{1}$, Jiankang Zhang ${ }^{1}$, Qiongfeng Shi ${ }^{2,3,4,5}$, Tianyiyi He ${ }^{2,3,4,5}$, Tao Chen ${ }^{1, *(1) \text {, }}$ \\ Lining Sun ${ }^{1}$, Jan A Dziuban ${ }^{6}$ and Chengkuo Lee ${ }^{2,3,4,5, *(D)}$ \\ 1 School of Mechanical and Electric Engineering, Jiangsu Provincial Key Laboratory of Advanced Robotics, \\ Soochow University, Suzhou 215123, China; hcliu078@suda.edu.cn (H.L.); \\ 20165229008@stu.suda.edu.cn (J.Z.); Insun@hit.edu.cn (L.S.) \\ 2 Department of Electrical \& Computer Engineering, National University of Singapore, 4 Engineering Drive 3, \\ Singapore 117576, Singapore; qiongfeng@u.nus.edu (Q.S.); tianyiyi@u.nus.edu (T.H.) \\ 3 Center for Intelligent Sensors and MEMS, National University of Singapore, E6 \#05-11F, \\ 5 Engineering Drive 1, Singapore 117608, Singapore \\ 4 Hybrid-Integrated Flexible (Stretchable) Electronic Systems Program, National University of Singapore, \\ E6 \#05-4, 5 Engineering Drive 1, Singapore 117608, Singapore \\ 5 National University of Singapore Suzhou Research Institute (NUSRI), Suzhou Industrial Park, \\ Suzhou 215123, China \\ 6 Faculty of Microsystem Electronics and Photonics, Wroclaw University of Science and Technology, \\ 11/17 Janiszewskiego Street, Wroclaw 50-372, Poland; jad@wtm.ite.pwr.wroc.pl \\ * Correspondence: chent@suda.edu.cn (T.C.); elelc@nus.edu.sg (C.L.)
}

Received: 6 July 2018; Accepted: 7 August 2018; Published: 9 August 2018

\begin{abstract}
A hybrid energy harvester is presented in this paper to harvest energy from water flow motion and temperature difference in an irrigating pipe at the same time. The harvester is based on the integration of thermoelectric and electromagnetic mechanisms. To harvest the water flow motion, a turbine fan with magnets that are attached on the blades is placed inside of the water pipe. Multiple coils turn the water flow energy into electricity with the rotation of the turbine. The thermoelectric generators (TEGs) are attached around the pipe, so as to harvest energy due to temperature difference. For a maximum temperature difference of $55^{\circ} \mathrm{C}$ (hot side $80^{\circ} \mathrm{C}$ and room temperature $25^{\circ} \mathrm{C}$ ), twelve serial-connected TEGs can generate voltage up to $0.346 \mathrm{~V}$. Under a load resistance of $20^{\prime} \Omega$, the power output of $1.264 \mathrm{~mW}$ can be achieved. For a maximum water flow rate of $49.9 \mathrm{~L} / \mathrm{min}$, the electromagnetic generator (EMG) can produce an open circuit voltage of $0.911 \mathrm{~V}$. The EMG can be potentially used as a water flow meter due to the linear relationship between water flow rate and output voltage. Under the joint action of TEG and EMG, the maximum terminal voltage for TEG is $66 \mathrm{mV}$ and for EMG is $241 \mathrm{mV}$ at load resistances of 10 and 100 ' $\Omega$, respectively, resulting in a corresponding power output of 0.435 and $0.584 \mathrm{~mW}$.
\end{abstract}

Keywords: hybrid energy harvester; water flow; thermoelectric; electromagnetic

\section{Introduction}

The irrigation systems have been widely used in agriculture [1]. Instead of irrigating the crops by manpower, various auto-irrigation methods are developed. Sprinkler irrigation is a kind of irrigation mode that spray the water with a certain pressure into the air and then disperse them into small water droplets or mist formation on the plants by water pumps and piping systems [2]. Sprinkler irrigation system can save water without destroying the soil structure and restriction by terrain. In the tropics, 
the temperature difference between irrigation water and surface temperature can reach to $35-55^{\circ} \mathrm{C}$ under sunlight during the dry season. The wasted heat can be utilized to generator power and make the irrigation system more intelligent. At present, various thermoelectric generators (TEGs) have been developed [3-7]. Xiong et al. [8] established a two-stage thermoelectric energy harvesting system to collect the waste heat from the blast furnace slag flushing water. The maximum power output of $0.44 \mathrm{~kW}$ is available for an inlet temperature of $100{ }^{\circ} \mathrm{C}$ with matched load resistance. He et al. [9] proposed a prototype of thermoelectric module that can generate electricity from the hot water in the pipe heated by solar energy. In irrigation system, water flow motion can also be utilized to generate electricity and power various sensor nodes in agricultural environment. The water flow energy harvesting is based on piezoelectric [10-13], electromagnetic [14-18], and triboelectric [19,20] approaches. Cho et al. [21] proposed a hydro electromagnetic and piezoelectric energy harvester to power a smart water meter system by transforming the water flow motion in the pipe into electricity, which consists of a turn-buckle type stainless steel waterwheel and two pole magnets. Wang et al. [22] also developed an electromagnetic energy harvester that integrates a Tesla disk turbine, a miniature axial-flux permanent magnet generator, and a ring cover with symmetrical grooves to generate electricity from non-directional water flow in oceans or rivers for remote sensors. In this study, a hybrid energy harvester is investigated to generate energy from the temperature difference and water flow motion in an irrigating pipe, which is based on thermoelectric and electromagnetic mechanisms. To make the irrigation system more intelligent, various sensor nodes or monitors can be added [23,24], e.g., temperature sensor [25] and flow meter [26]. By integrating the TEG and electromagnetic generator (EMG), the self-powered sensor nodes of the irrigation system will be realized in future.

\section{Design and Fabrication}

In the irrigation system, the diameter of a water pipe usually ranges from 15 to $40 \mathrm{~mm}$. In this work, the inner and outer diameter of the plastic water pipe are designed as 32 and $38 \mathrm{~mm}$, respectively. As shown in Figure 1a, the EMG is mounted at the end of the pipe. The rectangular holes on the side wall of the pipe are designed for TEG assembly. Twelve serial-connected TEGs are divided into two rows and are distributed around the water pipe evenly. The Peltier cooler (TE-8-0.45-1.3 from TE TECHNOLOGY, INC, Traverse City, MI, USA) is used as the TEG. The construction of TEG is shown in Figure 1b. As one side of the device is heated to a temperature greater than the other side, a voltage difference will be built up between the hot side and cold side. By referring to the specification, the effective working area of TEG is about $3.5 \mathrm{~mm} \times 3.5 \mathrm{~mm}$ and the size of each thermocouple (TC) is below $1 \mathrm{~mm}$. The components of EMG are coils, magnets, and turbine (Figure 1c). There are eight wound coils that are distributed evenly on the outer side walls of the pipe. The outer and inner diameter of the coil are 9.5 and $5.4 \mathrm{~mm}$, respectively, with 700 turns and wire diameter of $0.13 \mathrm{~mm}$. The resistance of each coil is about $26.8 \Omega$. The turbine of the cooling fan is used as the turbine of EMG. The frame of the cooling fan will be removed and only the fan part will be used as a turbine. The turbine is fixed to the frame of the water pipe and the magnets are fixed to the tip of turbine blades. The diameter and thickness of the turbine are 28 and $6.9 \mathrm{~mm}$, respectively. When the water flow drives the turbine rotate, the open circuit voltage will be generated in the surrounding coils. 

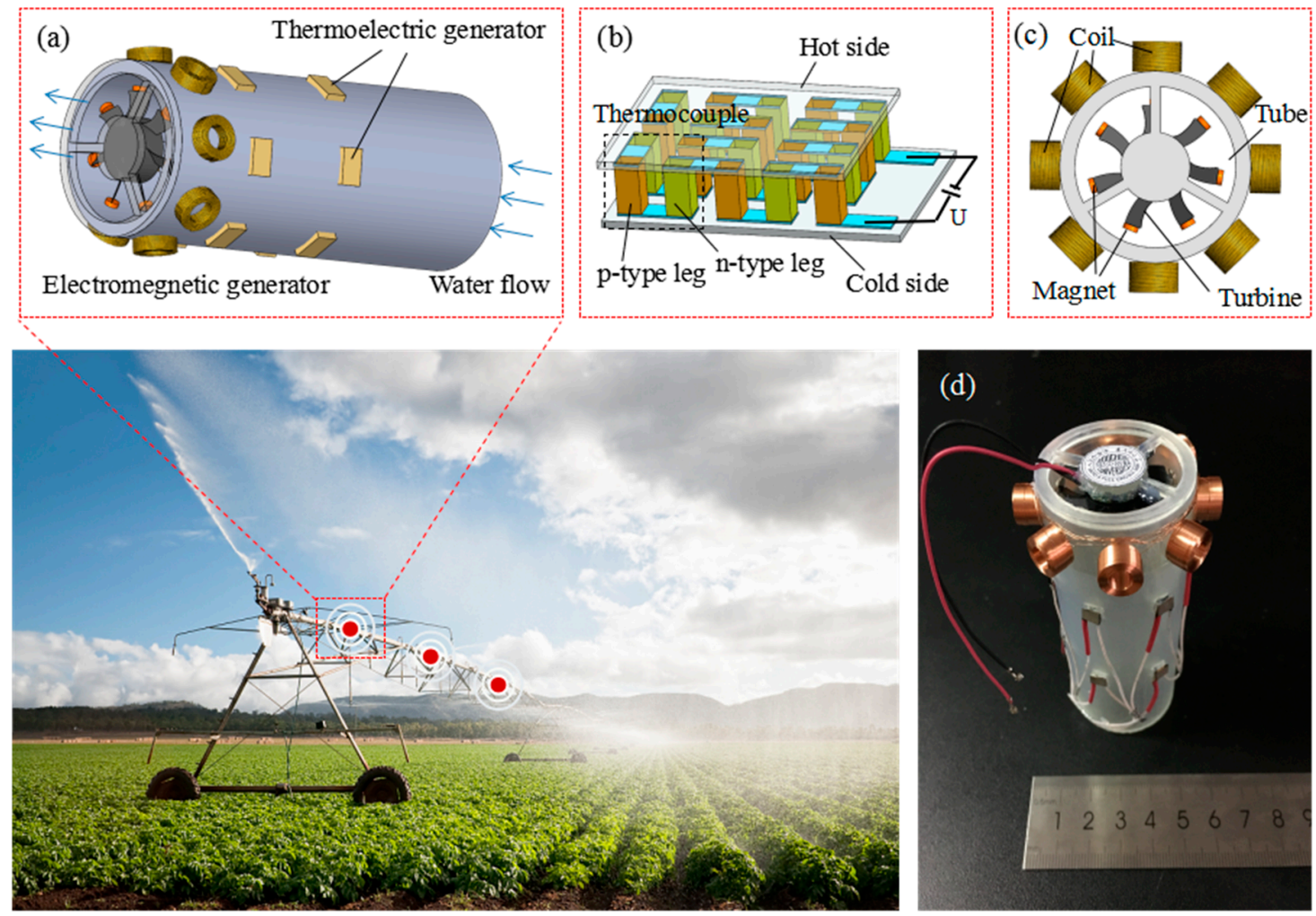

Figure 1. Diagram of hybrid energy harvester in irrigating pipe (a) Schematic diagram of hybrid energy harvester; (b) Three-dimensional (3-D) structure of thermoelectric generator (TEG); (c) Structural diagram of electromagnetic generator (EMG); and, (d) Photo of hybrid energy harvester.

\section{Working Principle and Simulation}

The mechanism of TEG is based on the direct conversion of heat to electrical power through the Seebeck effect [27]. When there is a heat source or a cooling source applied onto each individual side of the thermoelectric materials, electron/hole pairs will be created. A Seebeck voltage potential, which drives the hole/electron flow, is created by the temperature difference between the hot and cold sides of the thermoelectric elements. In a single TC, the net voltage appears between p-type and n-type legs. Since all of the TCs are connected in series, a total net voltage will eventually be produced. Figure $1 \mathrm{~b}$ shows the three-dimensional (3-D) structure of a TEG device. A number of TCs are connected electrically in series and thermally in parallel. As a temperature gradient is applied to the top and bottom sides, the sum of the Seebeck voltages of the TCs is induced at the generator terminals. The equation of open circuit voltage generated by TEG is as follows, which is proportional to the number of TCs $m$, the relative Seeback coefficient of the TC materials $\alpha$, and the temperature difference between cold and hot junctions $\Delta T_{G}$ :

$$
U_{0}=m \alpha \Delta T_{G}
$$

The principle for EMG is based on Faraday's law of electromagnetic induction [28]. It makes use of the magnetic flux $\Phi_{B}$ through a hypothetical surface $\Sigma$ whose boundary is a wire loop. Since the wire loop may be moving, $\Sigma$ is replaced by $\Sigma(t)$ for the surface. The magnetic flux is defined by a surface integral as:

$$
\Phi_{B}=\iint_{\Sigma(t)} B(r, t) \cdot \mathrm{d} A
$$

where $\mathrm{d} A$ is an element of surface area of the moving surface $\Sigma(t)$ and $B$ is the magnetic field (also called magnetic flux density). In more visual terms, the magnetic flux through the coil is proportional to 
the number of magnetic flux lines. When the magnetic flux changes, Faraday's law of electromagnetic induction says that the coil acquires an electromotive force (EMF). Equivalently, Faraday's law states that the EMF is also given by the rate of change of the magnetic flux [29]:

$$
\mathcal{E}=-N \frac{\mathrm{d} \Phi_{B}}{\mathrm{~d} t}
$$

where $\mathcal{E}$ is the EMF, $N$ is the number of turns, and $\Phi_{B}$ is the magnetic flux. The direction of the EMF is given by Lenz's law. In this paper, when the water in the pipe drive a turbine, the magnet on the tip of turbine blade will rotate, causing the change of magnetic flux across the coil, and the induced current will be produced (Figure 2a). The magnetic flux of one magnet across a single coil is simulated by COMSOL, assuming that the magnet and coil are concentric (Figure 2b). According to the simulation, the EMG can be optimized to increase the output power.

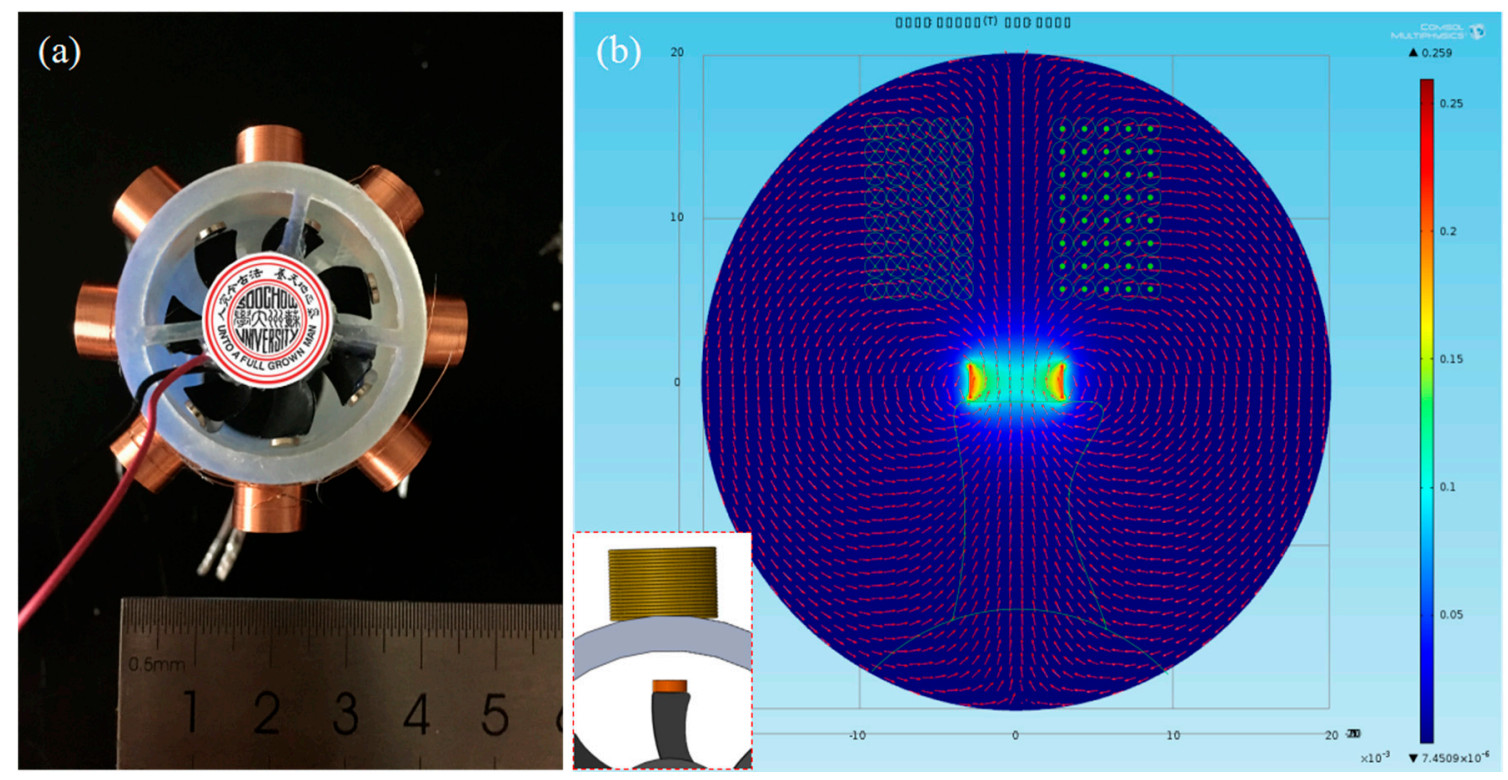

Figure 2. (a) Schematic diagram of EMG; and, (b) Simulation of the magnetic flux of one magnet across a single coil by COMSOL.

\section{Experiment and Optimization}

There are several aspects to the improvement of TEG: increase the Seebeck coefficient of the material, increase the surface temperature difference, and reduce the thermal conductivity of the material. Figure 3 demonstrates the comparison of the open circuit voltage when the hot side of TEG is placed directly on Aluminum (Al) and on thermal glue. The experiment result shows that at a hot side temperature of $58{ }^{\circ} \mathrm{C}$, the TEG placed on the $\mathrm{Al}$ tape directly generates a greater voltage of $46.75 \mathrm{mV}$, but the voltage drops very quickly. After $50 \mathrm{~s}$, the voltage decreases to $18.25 \mathrm{mV}$. The generated voltage of TEG placed on the thermal glue is $35 \mathrm{mV}$, which is lower than the other set. But, the voltage decreases much slower. After $50 \mathrm{~s}$, it still has a value of $32 \mathrm{mV}$. This is because Al has high thermal conductivity of up to $238 \mathrm{~W} /(\mathrm{m} \cdot \mathrm{K})$. Using $\mathrm{Al}$ tape to seal the holes on the pipe and putting the hot side of TEG directly on the Al tape help the temperature on the hot side increase fast. However, as time goes on, the cold side of TEG also heat up soon, causing the temperature difference to drop very quickly. Although thermal conductive glue has relatively lower thermal conductivity of $2.85 \mathrm{~W} /(\mathrm{m} \cdot \mathrm{K})$, it can keep the heat for a longer time. As a result, thermal glue is chosen in the subsequent tests. Figure 4 shows that at hot side temperatures of $55^{\circ} \mathrm{C}$ and $60{ }^{\circ} \mathrm{C}$ (Temperature differences of $23^{\circ} \mathrm{C}$ and $28^{\circ} \mathrm{C}$, respectively), TEG with thermal grease attached on the cold side has open circuit voltages of 21 and $31 \mathrm{mV}$, respectively, while TEG without thermal grease has lower voltages of 15 and $27 \mathrm{mV}$, 
respectively. The thermal conductivity of thermal grease is about $4.85 \mathrm{~W} /(\mathrm{m} \cdot \mathrm{K})$. The aim of applying thermal grease on the cold side of TEG is to increase the speed of heat dissipation on the surface, so that the temperature difference between the cold side and the hot side will not decrease rapidly. Therefore, in the subsequent tests, thermal conductive glue and thermal grease are applied on the hot side and cold side, respectively.

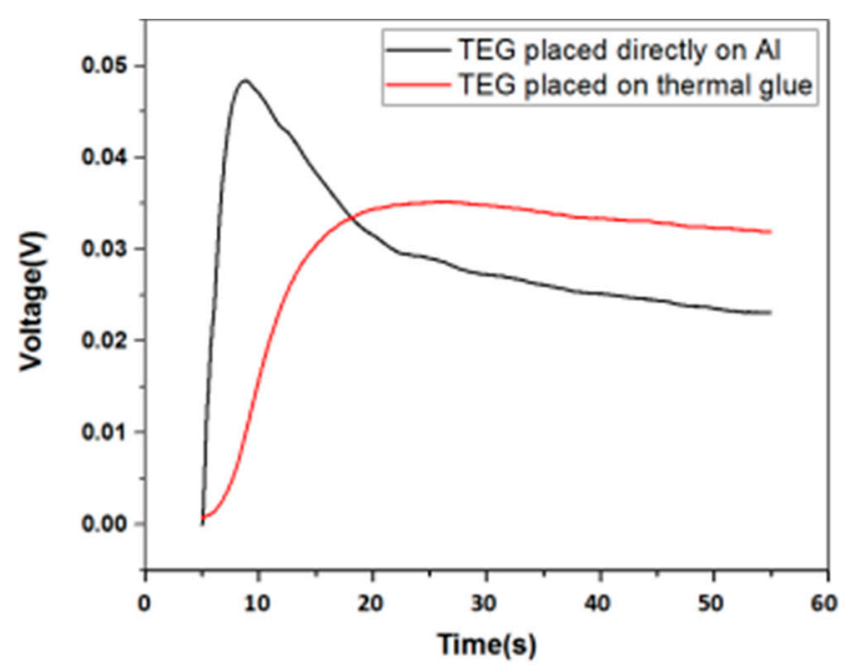

Figure 3. Open circuit voltages of TEG with the hot side placed directly on $\mathrm{Al}$ and on thermal glue.

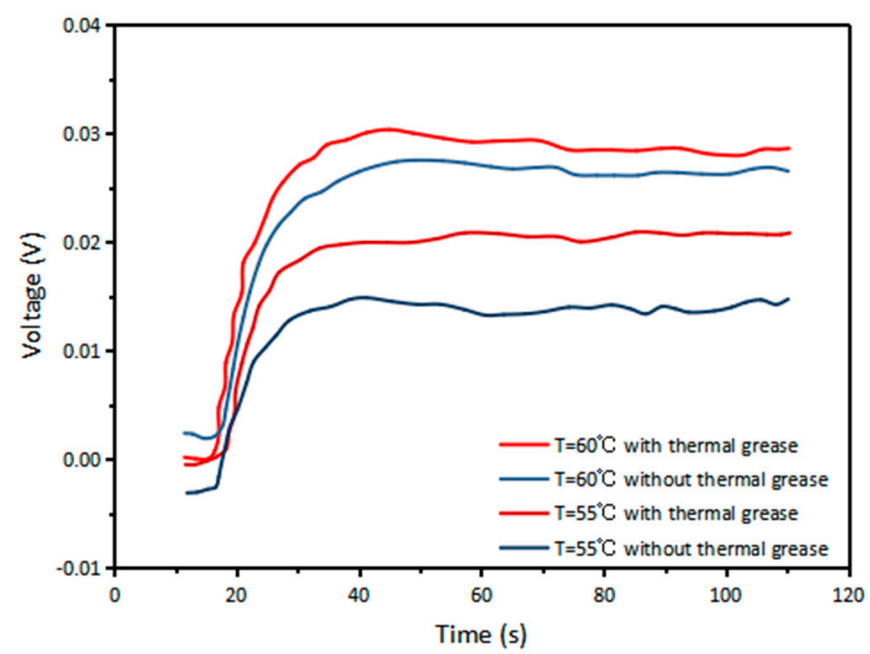

Figure 4. Open circuit voltages of TEG with and without thermal grease attached on the cold side.

As the TEGs are expected to work for a relative continuous time, the stability of the output voltage of the TEGs over a time period is evaluated. Figure 5 shows the open circuit voltages generated by five TEGs in series with different hot side temperatures. At first, the hot water is poured inside the pipe, TEGs start to generate voltage and reach to a maximum value. Then, the voltage decreases slowly with time. After $200 \mathrm{~s}$, TEGs still have the ability to maintain about $80 \%$ of its maximum voltage output (Table 1). The twelve TEG components are connected in series and their terminal voltages and power are tested in terms of different hot side temperatures. 


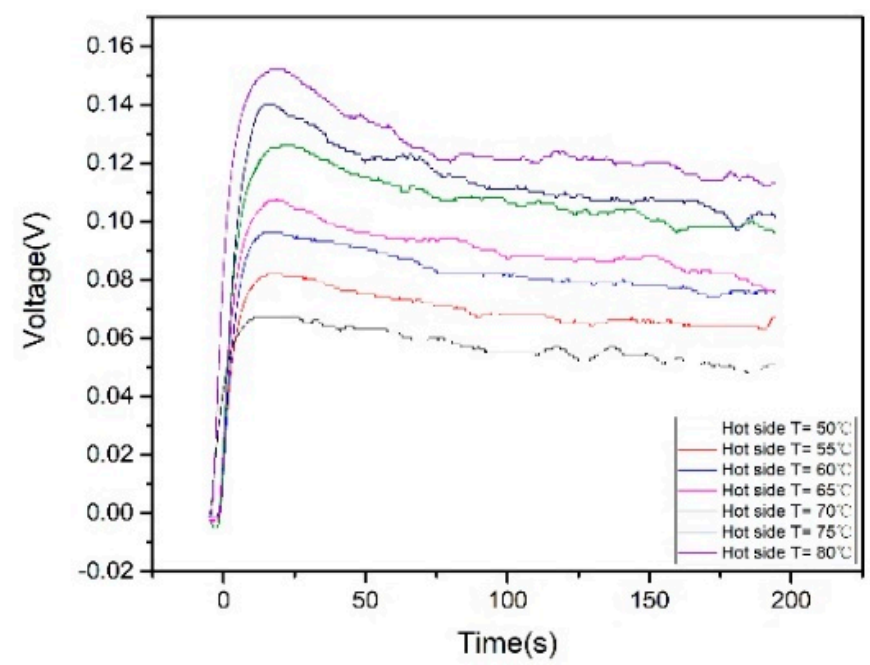

Figure 5. Open circuit voltages of TEGs with different hot side temperatures.

Table 1. Performance of TEGs with different hot side temperatures.

\begin{tabular}{cccc}
\hline $\begin{array}{c}\text { Hot Side } \\
\text { Temperature }\left({ }^{\circ} \mathbf{C}\right)\end{array}$ & $\begin{array}{c}\text { Maximum Open Circuit } \\
\text { Voltage (mV) }\end{array}$ & $\begin{array}{c}\text { Voltage after } \\
\text { 200 s (mV) }\end{array}$ & Percentage \\
\hline 80 & 155 & 114.025 & $73.56 \%$ \\
75 & 147 & 109.225 & $74.30 \%$ \\
70 & 131 & 102.275 & $78.07 \%$ \\
65 & 110 & 83.15 & $75.59 \%$ \\
60 & 97 & 77.375 & $79.77 \%$ \\
55 & 86 & 69.025 & $80.20 \%$ \\
50 & 69 & 53.75 & $77.90 \%$ \\
\hline
\end{tabular}

Figure $6 \mathrm{a}$ is the experimental results of the terminal voltage against different load resistances. The voltage increases rapidly as the load resistance rises, then it undergoes slow increment at higher load resistance. The largest voltages for hot side temperatures of $50^{\circ} \mathrm{C}, 65^{\circ} \mathrm{C}, 70^{\circ} \mathrm{C}$, and $80^{\circ} \mathrm{C}$ are 149 , 229,282 , and $346 \mathrm{mV}$, respectively. Figure $6 \mathrm{~b}$ shows the power changes with increasing load resistances. The maximum power outputs for $50^{\circ} \mathrm{C}, 65^{\circ} \mathrm{C}, 70^{\circ} \mathrm{C}$, and $80^{\circ} \mathrm{C}$ are $0.254,0.353,0.605$, and $1.264 \mathrm{~mW}$, respectively, under load resistances of $15,19,20$, and $22 \Omega$.

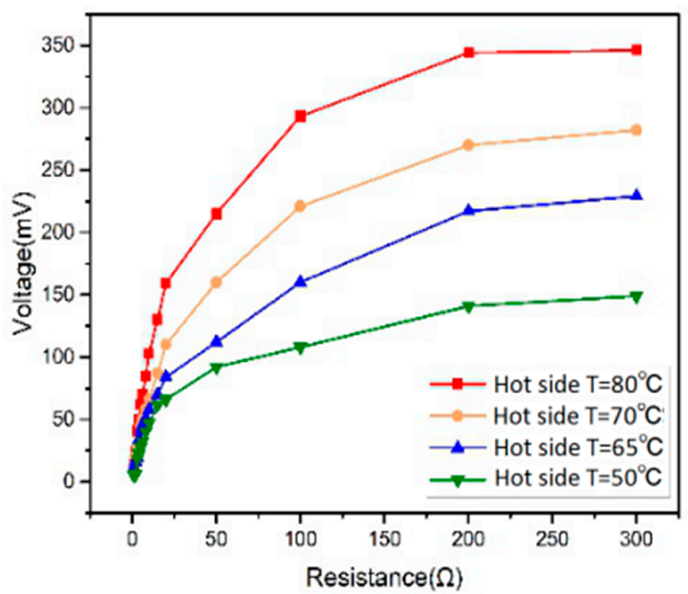

(a)

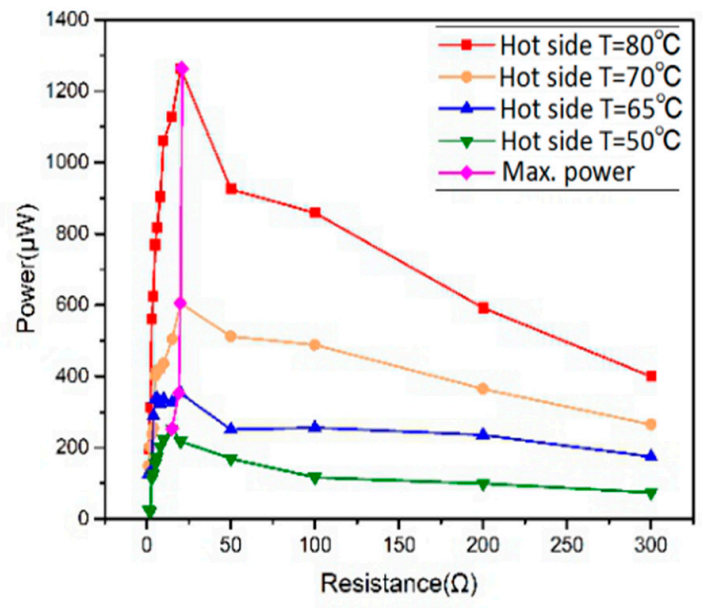

(b)

Figure 6. (a) Voltage and (b) power outputs of TEGs under different load resistances. 
In order to improve the output performance of EMG, the number of magnets on the tip of the turbine blade and the direction of the magnetic pole are taken into consideration. In the single-magnet set, the D3 $\times 1 \mathrm{~mm}$ magnets are placed on the blade in opposite direction. To be specific, the N-pole of a magnet on one blade is placed outward and the $\mathrm{N}$-pole of the magnet on next blade is placed inward. In the double-magnet set, the D2 $\times 1 \mathrm{~mm}$ magnets are placed on the blade in pairs. All of the output voltages of EMG in this paper are peak-to-peak voltages. Figure 7 shows that as the flow rate increases from 10 to $45 \mathrm{~L} / \mathrm{min}$, the generated voltage of EMG increases gradually to $527 \mathrm{mV}$ with the magnets being placed in opposite direction, while the maximum voltage of EMG with double-magnet set is only $196 \mathrm{mV}$. It is found that the voltage output of EMG with single-magnet blade is about twice times higher than that with the double-magnet blade.

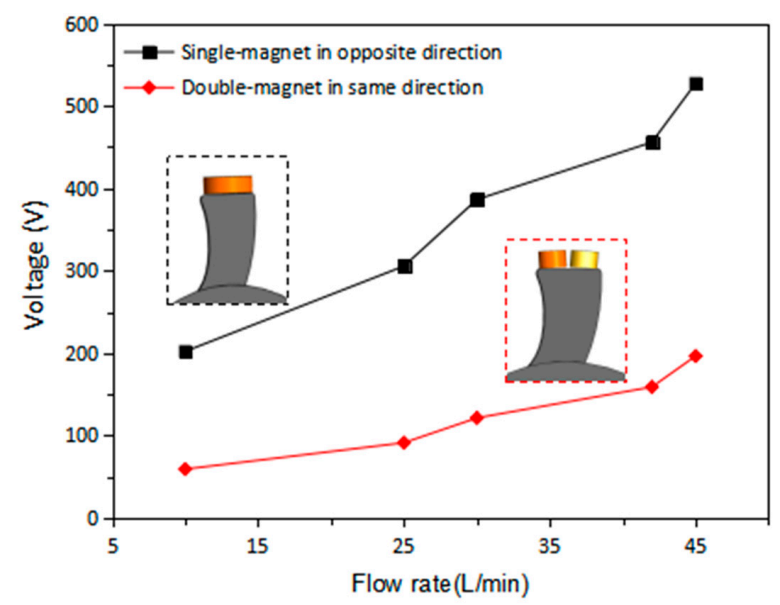

Figure 7. Open circuit voltage of EMG for single-magnet in opposite direction and double-magnet in same direction.

Figure 8 shows the terminal voltage and power outputs of EMG with different load resistances. From Figure 8b, the maximum power of $0.127,0.362$, and $0.673 \mathrm{~mW}$ for flow rate of 10,25 , and $30 \mathrm{~L} / \mathrm{min}$ are achieved at load resistances of 100,150, and $180 \Omega$, respectively. Figure 9 shows the voltage and power of EMG versus flow rate under matched load resistance of $100 \Omega$. At flow rate of $49.5 \mathrm{~L} / \mathrm{min}$, the maximum voltage is $302 \mathrm{mV}$ and the corresponding power output is $0.912 \mathrm{~mW}$. It can be observed that there is an approximately linear relationship between the output voltage of EMG and water flow rate. Therefore, it could be a potential application for EMG to be the self-powered water flow meter in irrigation system.

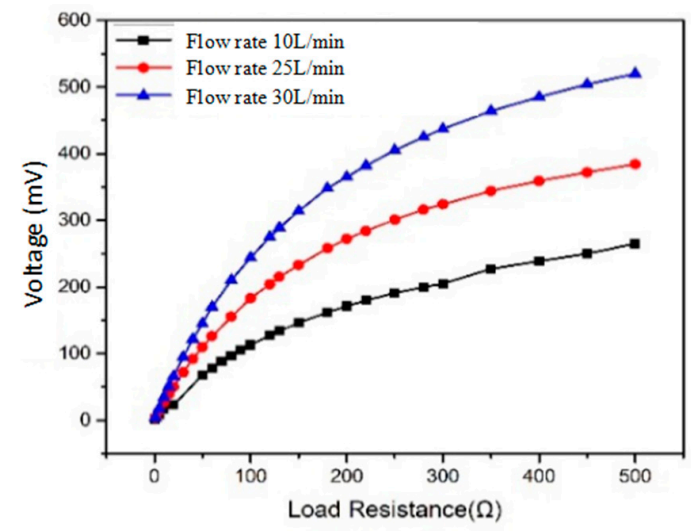

(a)

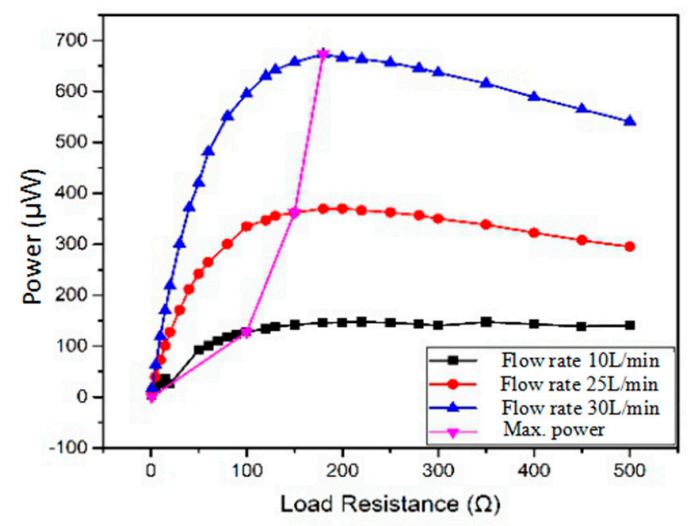

(b)

Figure 8. (a) Voltage and (b) power of EMG with different load resistances. 


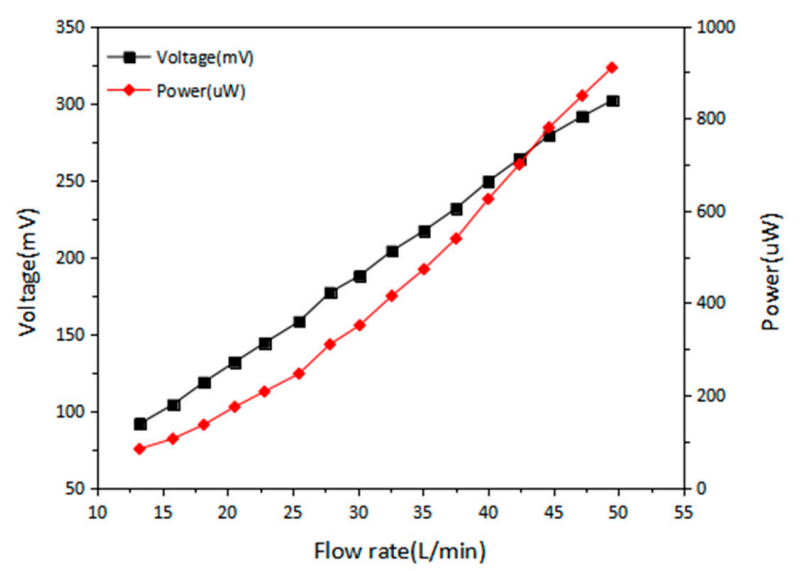

Figure 9. Terminal voltage and power of EMG against water flow rate.

The integral testing setup is shown in Figure 10, and the output of TEGs and EMG are collected by the oscilloscope. In this scenario, hot water of $60^{\circ} \mathrm{C}$ are adopted. Figure 11 a shows the voltage waveforms of EMG and TEG. The open circuit voltage of TEGs is $157 \mathrm{mV}$ and EMG is $911 \mathrm{mV}$. Figure $11 \mathrm{~b}$ shows a demonstrative graph from oscilloscope when load resistances of 10 and $100 \Omega$ are added to the TEG and EMG circuit, respectively, with a hot side temperature of $60{ }^{\circ} \mathrm{C}$ and a flow rate of $38 \mathrm{~L} / \mathrm{min}$. The maximum terminal voltages from TEG and EMG are 66 and $241.7 \mathrm{mV}$, respectively, resulting in power outputs of 0.436 and $0.584 \mathrm{~mW}$.

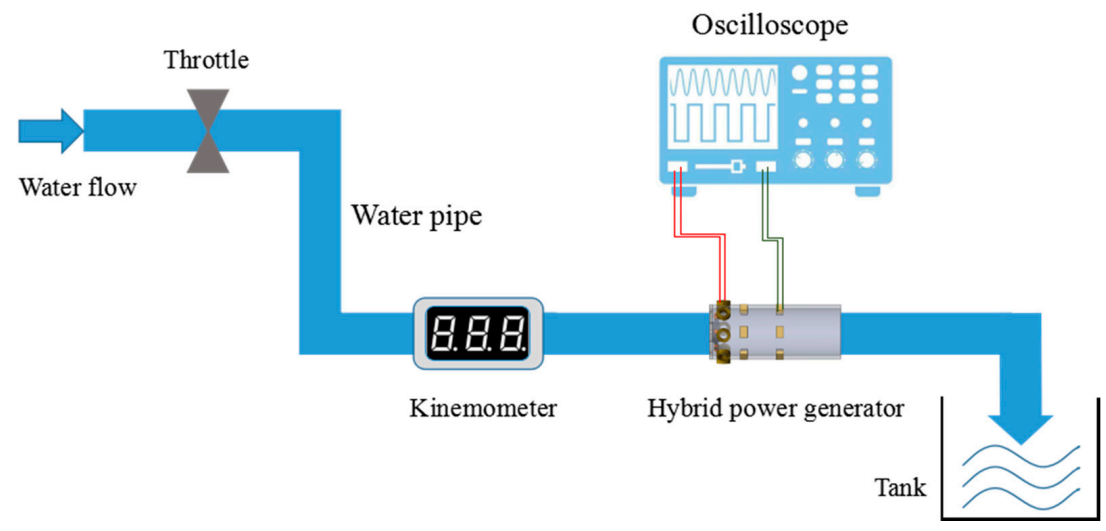

Figure 10. Testing scenario of the collective performance of TEG and EMG.

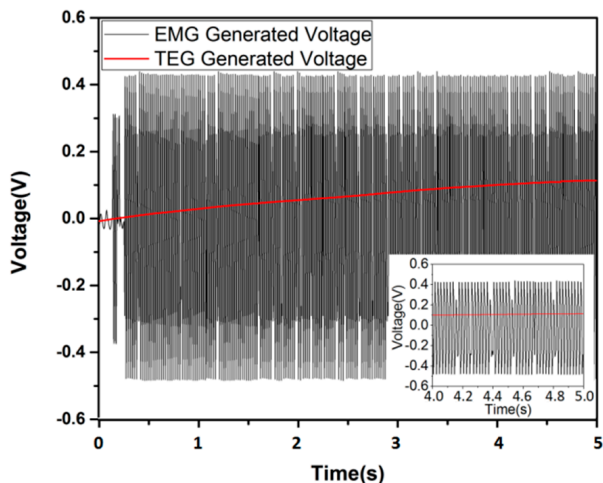

(a)

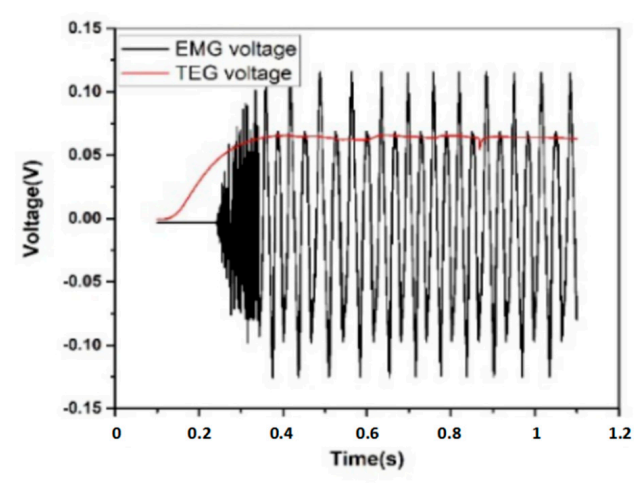

(b)

Figure 11. (a) Collective open circuit voltage of EMG and TEG; and, (b) Collective output voltage of TEG and EMG under load resistance of 10 and $100 \Omega$. 


\section{Conclusions}

This paper presents a hybrid power generator applied in an irrigation system. It integrates the TEGs with water-flow-driven EMG. For the TEG part, it turns out that the TEG performance is improved by putting hot side of TEG on the thermal conductive glue and applying thermal grease on the cold side. For the EMG part, a cooling fan is chosen as the water turbine and the way that placing the single-magnet in opposite direction has a larger output voltage. The result shows that the generated voltage is strongly increased to $527 \mathrm{mV}$. After the improvement, the TEG and EMG are tested in hot flowing water. For TEG, the experiment shows that the adopted TEG set can have a lasting voltage output over $200 \mathrm{~s}$ and maintain about $80 \%$ of the maximum output. The largest voltages generated for a twelve TEG set at hot side temperatures of $50^{\circ} \mathrm{C}, 65^{\circ} \mathrm{C}, 70{ }^{\circ} \mathrm{C}$, and $80^{\circ} \mathrm{C}$ are $149,229,282$, and $346 \mathrm{mV}$, respectively, and the power are $0.254,0.353,0.605$, and $1.264 \mathrm{~mW}$, under load resistances of $15,19,20$, and $22 \Omega$. For EMG, the water flow rate and the resulting open circuit voltage follow a linear relationship so that the EMG can be also used as flowmeter. At a flow rate of $49.51 \mathrm{~L} / \mathrm{min}$, the maximum voltage is $302 \mathrm{mV}$ and the resulting power output is $0.912 \mathrm{~mW}$ with the load resistance of $100 \Omega$. The collective output is finally tested, with $60^{\circ} \mathrm{C}$ flowing hot water at a flow rate of $38 \mathrm{~L} / \mathrm{min}$. When load resistances of 10 and $100 \Omega$ are added, the maximum terminal voltage for TEG is $66 \mathrm{mV}$ and for EMG is $241.7 \mathrm{mV}$, resulting in power outputs of 0.436 and $0.584 \mathrm{~mW}$. Thus, the total output power is better than $1 \mathrm{~mW}$, which is sufficient for supporting the power consumption of typical low-power wireless transmission modules that are used in sensor network applications.

Author Contributions: Conceptualization-T.C.; Formal analysis-Q.S.; Investigation-J.Z.; Methodology-T.H.; Project administration-L.S.; Resources-C.L.; Supervision-H.L.; Validation-J.A.D.

Funding: This work is funded by the National Science Foundation of China (Grant No. 41527901 and No. 61673287); Qingdao National Laboratory for Marine Science and Technology (Grant No. 2017ASKJ01); China Jiangsu Provincial Key R\&D (Grant No. BE2016077); HIFES Seed Funding-2017-01 grant (R-263- 501-012-133) "Hybrid Integration of Flexible Power Source and Pressure Sensors" at the National University of Singapore; Agency for Science, Technology and Research (A*STAR), Singapore and Narodowe Centrum Badań i Rozwoju (NCBR), Poland Joint Grant (R-263-000-C91-305) “Chip-Scale MEMS Micro-Spectrometer for Monitoring Harsh Industrial Gases".

Conflicts of Interest: The authors declare no conflicts of interest.

\section{References}

1. Li, W. Design of wireless water-saving irrigation system based on solar energy. In Proceedings of the 2011 International Conference on Control, Automation and Systems Engineering (CASE), Singapore, 30-31 July 2011.

2. Mitralexis, G.; Goumopoulos, C. Web based monitoring and irrigation system with energy autonomous wireless sensor network for precision agriculture. In Proceedings of the 2015 European Conference on Ambient Intelligence, Athens, Greek, 11-13 November 2015; pp. 361-370.

3. Yang, S.M.; Lee, T.; Cong, M. Design and verification of a thermoelectric energy harvester with stacked polysilicon thermocouples by CMOS process. Sens. Actuators A Phys. 2010, 157, 258-266. [CrossRef]

4. Wan, Q.; Teh, Y.K.; Gao, Y.; Mok, P.K. Analysis and design of a thermoelectric energy harvesting system with reconfigurable array of thermoelectric generators for IoT applications. IEEE Trans. Circuits Sys. I Regul. Pap. 2017, 99, 1-13. [CrossRef]

5. Shi, Y.; Wang, Y.; Mei, D.; Feng, B.; Chen, Z. Design and fabrication of wearable thermoelectric generator device for heat harvesting. IEEE Robot. Autom. Lett. 2018, 3, 373-378. [CrossRef]

6. Yun, G.S.; Leong, K.S.; Rahman, M.F.B.A. Development of self-powered thermoelectric based RF transmitter circuit. In Proceedings of the 2016 IEEE International Conference on Power and Energy (PECon), Melaka, Malaysia, 28-29 November 2016; pp. 439-443.

7. Saida, M.; Zaibi, G.; Samet, M.; Kachouri, A. A new design of thermoelectric generator for health monitoring. In Proceedings of the 2017 International Conference on Smart, Monitored and Controlled Cities (SM2C), Sfax, Tunisia, 17-19 February 2017; pp. 59-63.

8. Xiong, B.; Chen, L.; Meng, F.; Sun, F. Modeling and performance analysis of a two-stage thermoelectric energy harvesting system from blast furnace slag water waste heat. Energy 2014, 77, 562-569. [CrossRef] 
9. He, W.; Su, Y.; Wang, Y.Q.; Riffat, S.B.; Ji, J. A study on incorporation of thermoelectric modules with evacuated-tube heat-pipe solar collectors. Renew. Energy 2012, 1, 142-149. [CrossRef]

10. Zhang, M.; Liu, Y.; Cao, Z. Modeling of piezoelectric energy harvesting from freely oscillating cylinders in water flow. Math. Probl. Eng. 2014, 2014, 1-13. [CrossRef]

11. Molino-Minero-Re, E.; Carbonell-Ventura, M.; Fisac-Fuentes, C.; Mànuel-Làzaro, A.; Toma, D.M. Piezoelectric energy harvesting from induced vortex in water flow. In Proceedings of the 2012 Instrumentation and Measurement Technology Conference, Graz, Austria, 13-16 May 2012; pp. 624-627.

12. Karami, M.A.; Farmer, J.R.; Inman, D.J. Parametrically excited nonlinear piezoelectric compact wind turbine. Renew. Energy 2013, 50, 977-987. [CrossRef]

13. Chen, T.; Xia, Y.; Liu, W.; Liu, H.; Sun, L.; Lee, C. A hybrid flapping-blade wind energy harvester based on vortex shedding effect. J. Microelectromech. Syst. 2016, 25, 845-847. [CrossRef]

14. Boisseau, S.; Duret, A.B.; Perez, M.; Jallas, E.; Jallas, E. Water flow energy harvesters for autonomous flowmeters. J. Phys. Conf. Ser. 2016, 773, 012019. [CrossRef]

15. Adamski, K.; Adamski, J.; Dziuban, J.A.; Walczak, R. Inkjet 3D printed miniature water turbine as flow meter and energy harvester for wireless sensor system. In Proceedings of the 21st International Conference on Miniaturized Systems for Chemistry and Life Sciences, Savannah, GA, USA, 22-26 October 2017.

16. Hoffmann, D.; Willmann, A.; Göpfert, R.; Becker, P.; Folkmer, B.; Manoli, Y. Energy harvesting from fluid flow in water pipelines for smart metering applications. J. Phys. Conf. Ser. 2013, 476, 012104. [CrossRef]

17. Liao, L.D.; Chao, P.C.P.; Chen, J.T.; Chen, W.D.; Hsu, W.H.; Chiu, C.W.; Lin, C.T. A miniaturized electromagnetic generator with planar coils and its energy harvest circuit. IEEE Trans. Magn. 2009, 45, 4621-4627. [CrossRef]

18. Bansal, A.; Howey, D.A.; Holmes, A.S. Cm-scale air turbine and generator for energy harvesting from low-speed flows. In Proceedings of the 2009 International Solid-State Sensors, Actuators and Microsystems Conference, Denver, CO, USA, 21-25 June 2009; pp. 529-532.

19. Ahmed, A.; Saadatnia, Z.; Hassan, I.; Zi, Y.; Xi, Y.; He, X.; Zu, J.; Wang, Z. Self-powered wireless sensor node enabled by a duck-shaped triboelectric nanogenerator for harvesting water wave energy. Adv. Energy Mater. 2016, 7, 1601705. [CrossRef]

20. Xie, Y.; Wang, S.; Lin, L.; Jing, Q.; Lin, Z.H.; Niu, S.; Wu, Z.; Wang, Z. Rotary triboelectric nanogenerator based on a hybridized mechanism for harvesting wind energy. ACS Nano 2013, 7, 7119-7125. [CrossRef] [PubMed]

21. Cho, J.Y.; Choi, J.Y.; Jeong, S.W.; Ahn, J.H.; Hwang, W.S.; Yoo, H.H.; Sung, T.H. Design of hydro electromagnetic and piezoelectric energy harvesters for a smart water meter system. Sens. Actuators A Phys. 2017, 261, 261-267. [CrossRef]

22. Wang, T.; Zhang, Y. Design, analysis, and evaluation of a compact electromagnetic energy harvester from water flow for remote sensors. Energies 2018, 11, 1424. [CrossRef]

23. Alammri, A.S.; Ridah, S. Smart irrigation system using wireless sensor network. Int. J. Eng. Res. Technol. 2014, 3, 2278.

24. Futagawa, M.; Iwasaki, T.; Murata, H.; Ishida, M.; Sawada, K. A miniature integrated multimodal sensor for measuring $\mathrm{pH}, \mathrm{EC}$ and temperature for precision agriculture. Sensors 2012, 12, 8338-8354. [CrossRef] [PubMed]

25. Awu, J.I.; Mbajiorgu, C.C.; Michael, O.; James, D.D.; Anyaeji, F.O.; Willoughby, F.A.; Eneh, C.K. Development of a low cost digital turbine water flow meter for irrigation farm. Int. J. Basic Appl. Sci. 2017, 6, 92-97.

26. Ihring, A.; Kessler, E.; Dillner, U.; Schinkel, U.; Kunze, M.; Billat, S. A planar thin-film peltier cooler for the thermal management of a dew-point sensor system. J. Microelectromechan. Syst. 2015, 24, 990-996. [CrossRef]

27. Su, J.; Vullers, R.J.; Goedbloed, M.; van Andel, Y.; Leonov, V.; Wang, Z. Thermoelectric energy harvester fabricated by stepper. Microelectron. Eng. 2010, 87, 1242-1244. [CrossRef]

28. Kwon, S.D.; Park, J.; Law, K. Electromagnetic energy harvester with repulsively stacked multilayer magnets for low frequency vibrations. Smart Mater. Struct. 2013, 22, 055007. [CrossRef]

29. Liu, H.; Xia, Y.; Chen, T.; Yang, Z.; Liu, W.; Wang, P.; Sun, L. Study of a hybrid generator based on triboelectric and electromagnetic mechanisms. IEEE Sens. J. 2017, 17, 3853-3860. [CrossRef]

(C) 2018 by the authors. Licensee MDPI, Basel, Switzerland. This article is an open access article distributed under the terms and conditions of the Creative Commons Attribution (CC BY) license (http:/ / creativecommons.org/licenses/by/4.0/). 